This document is published in:

Materials Science and Engineering: A, March 2012, vol. 538, pp. 28-34

DOI: http://dx.doi.org/10.1016/j.msea.2011.12.107 .

(C) Elsevier 


\title{
Microstructural development and mechanical properties of iron based cermets processed by pressureless and spark plasma sintering
}

\author{
P. Alvaredo ${ }^{(\mathrm{a})} ;$ E. Gordo ${ }^{\left(\mathrm{a}^{\star}\right)} ;$ O. Van der Biest ${ }^{(\mathrm{b})} ;$ K. Vanmeensel ${ }^{(\mathrm{b})}$
}

(a) Department of Materials Science and Engineering, IQMAAB, University Carlos III Madrid. Avda. de la Universidad, 30, 28911 Leganés (Spain)

(b) Katholieke Universiteit Leuven. Kasteelpark Arenberg, 443001 Heverlee (Belgium)

- Corresponding author. Tel. +34916248862; Fax.: +34916249430. Email: elena.gordo@uc3m.es

\begin{abstract}
Iron-based cermets are an interesting class of metal-ceramic composites which properties and the factors influencing then are to be explored. In this work the metal matrix contains $\mathrm{Cr}, \mathrm{W}$, Mo and $\mathrm{V}$ as alloying elements, and the hard phase is constituted by 50 vol \% of titanium carbonitride (TiCN) particles. The work studies the influence of the $C$ content and the processing method on the sinterability, microstructure and hardness of the developed cermet materials. For that purpose, cermet samples with different $C$ content in the matrix (0 wt $\%, 0.25 \mathrm{wt} \%, 0.5 \mathrm{wt} \%, 1.0 \mathrm{wt} \%)$ were prepared by conventional pressureless sintering (CPS) and, in order to achieve finer microstructures and to reduce the sintering time, by Spark Plasma Sintering (SPS). The density and hardness (HV30) of the processed materials was evaluated, while their phase composition and microstructure was characterised by X-Ray Diffraction (XRD) and Scanning Electron Microscopy (SEM), respectively. The equilibrium phase diagram of the composite material was calculated by ThermoCalc software in order to elucidate the influence of the carbon content on the obtained phases and developed microstructures.
\end{abstract}

\section{Keywords}

Composites, ferrous alloys, phase transformation, powder metallurgy, sintering.

\section{Introduction}

Cermets based on titanium carbonitride are usually composed of TiCN particles embedded in a $\mathrm{Ni}$ and/or Co metallic matrix [1]. TiCN based cermets are preferred over traditional WC-Co based hardmetals because of their higher thermal and chemical stability and their excellent combination of hot hardness, oxidation resistance and toughness [2,3,4]. Ni and/or Co are normally used as metallic binder in these composite materials although there is an increasing interest to substitute them by other elements, among which $\mathrm{Fe}$ is the most interesting candidate [5].The use of iron presents several advantages over $\mathrm{Co}$ or $\mathrm{Ni}$, including non-toxicity, abundance of resources leading to lower cost and the ability to be hardened by heat treatment, which could lead to a high hardness with a lower quantity of ceramic phase [6]. However, Fe-based cermets present low sintering performance due to the poor wettability of the liquid phase and the risk of producing reaction products that lead to embrittlement [7]. The addition of some alloying elements such as $\mathrm{Mo}, \mathrm{Cr}$ and W $[8,9]$, or compounds such as $\mathrm{Mo}_{2} \mathrm{C}$ or WC $[10,11]$ to TiCN-based cermets have been reported to improve the sintering performance by improving the wettability between the ceramic and the liquid phase. For the latter reason, a commercial alloy designated as high speed steel, grade M2, containing $\mathrm{Cr}, \mathrm{W}, \mathrm{Mo}$ and $\mathrm{V}$ as alloying elements, was selected as matrix phase. Materials related with these can be found in the market, for wear resistant applications. They are composed by Fe alloys as matrix and TiC as reinforcement, and are commercialized as FerroTitanit ${ }^{\circledR}$ and FerroTiC ${ }^{\circledR}$.

TiCN-based cermets are usually produced by the conventional route of pressing and vacuum sintering (CPS). However, fast coarsening of the microstructure usually occurs due to the high 
sintering temperatures needed resulting in liquid phase formation, which is characterised by dissolution-reprecipitation phenomena, as well as in changes in the $\mathrm{C} / \mathrm{N}$ ratio of the TiCN particles, leading to changes in mechanical and physical properties.

Therefore, it is of interest to investigate a different sintering technique that could minimise grain growth and control the nitrogen quantity in the TiCN structure, since N has been reported in other investigations as a grain growth inhibitor [12]. In this work Spark Plasma Sintering (SPS), which involves the sintering of powders under the simultaneous use of a current and pressure, was used. Typically, powders are placed in a die and heating is performed by passing a current (typically pulsed DC) through the die and the sample (if the latter is conducting) while a pressure is applied on the powder compact. The characteristics of the SPS process, therefore, include high heating rate, the application of a pressure and the effect of the current [13 14].

The SPS technique presents numerous benefits in terms of material processing compared to conventional vacuum sintering: (1) In situ cleaning the surfaces of powder particles leading to the removal of the surface oxides and entrapped gas and resulting in an improvement of the wettability of the phases, promoting atomic diffusion and accelerating the consolidation process, (2) The high pulsed DC current is directly applied to the graphite die, so that the sintering powder compact can be heated up and cooled down extremely fast, greatly shortening the exposure time at high temperature, hereby preserving a fine microstructure and preventing grain growth so as to obtain fine and even nano-structured materials and(3) The combination of multiple sintering driving forces can lower the sintering temperature and consolidate powders in a short time and achieve high or full densification [15].

Many research works have highlighted the influence of the carbon content on the properties of TiCN-based cermets $[16,17,18,19]$. These works refers to Co/Ni matrices, but no investigations have been found for Fe based matrices. It is expected that the $\mathrm{C}$ content influences the properties of Fe-TiCN cermets in different ways such as changes in the steel matrix phases, carbide precipitation and composition as well as $\mathrm{C} / \mathrm{N}$ ratio of the TiCN phase. The aim of this study is to investigate and compare the influence of the carbon content on the microstructure and properties of an iron-based cermet reinforced with TiCN processed by either Spark Plasma Sintering or by the conventional powder metallurgical route. Thermodynamic simulations, performed using ThermoCalc software, have been used to calculate the phase diagram for the proposed cermet. Although it is expected that non-equilibrium phase compositions will be obtained after SPS processing, due to the high heating and cooling rates applied, it is a useful tool to explain some microstructural, crystallographic and mechanical property differences observed between the processed materials processed by either of the two different sintering techniques.

\section{Experimental procedure}

The investigated composite materials consist of an Fe alloy based matrix and 50 vol\% of $\mathrm{TiC}_{0.5} \mathrm{~N}_{0.5}$ particles as a reinforcement phase. The composition of the Fe alloy is $6.2 \mathrm{wt} \% \mathrm{~W}, 4.8 \mathrm{wt} \% \mathrm{Mo}, 4.1$ $\mathrm{wt} \% \mathrm{Cr}, 1.8 \mathrm{wt} \% \mathrm{~V}$ and $0.85 \mathrm{wt} \% \mathrm{C}$, which corresponds to the high-speed steel grade $\mathrm{M} 2$, used as prealloyed powder, as it contains all the elements desired for the matrix. To study the effect of the carbon content, different amounts of graphite were added to the matrix leading to materials with composition $[\mathrm{M} 2+\mathrm{X}$ wt $\% \mathrm{C}]+\mathrm{TiCN} 50$ vol $\%$, where $\mathrm{X}$ is $0,0.25,0.5$ and 1 . The density and particle size of the starting powders are given in Table 1

Table 1. Characteristics of raw materials.

The powders were blended during 4 hours in a Turbula ${ }^{\circledR}$ multidirectional mixer. Samples processed by the conventional powder metallurgy route (CPS) were pressed uniaxially at $700 \mathrm{MPa}$ into rectangular bars $(31,6 \times 12,9 \times 4 \mathrm{~mm})$ and sintered at $1400^{\circ} \mathrm{C}$ during 60 minutes under vacuum $\left(10^{-4} \mathrm{mbar}\right)$. The equipment used for processing the samples by SPS was a Type HP D25/1, FCT Systeme, Rauenstein, Germany. The samples were made by pouring $25 \mathrm{~g}$. of powder mixture into a $30 \mathrm{~mm}$ diameter tool set-up made of graphite. The SPS processing conditions chosen after a preliminary study were a maximum temperature of $1100^{\circ} \mathrm{C}$, under a pressure of $60 \mathrm{MPa}$ during 10 
minutes in vacuum. The temperature during the SPS process was measured with a Pyrometer (Impac, $400-2300^{\circ} \mathrm{C}$ ) focussing at the bottom of a central bored hole in the upper punch about 2 $\mathrm{mm}$ from the top surface of the sample. A thermal carbon felt insulation was used to surround the die to avoid thermal gradients inside the sample during sintering.

The density of the processed samples was measured by He pycnometry, while the Vickers hardness was obtained from $30 \mathrm{~kg}$ indentations. X Ray diffraction and scanning electron microscopy (SEM) were used for crystallographic and microstructural analysis, respectively

A thermodynamic study of the equilibrium phase diagram of the cermet was performed using ThermoCalc software [20]. Calculations are based on the Gibbs free energy minimization code and mass conversion rule, in combination with the TCFE5 database (Scientific Group Thermodata Europe). For the calculation, the elements $\mathrm{Ti}, \mathrm{C}$ and $\mathrm{N}$ were introduced in the mass percentages that correspond to a mixture containing M2/TiCN of 50 vol\% each. The amount of $\mathrm{C}$ was varied considering the additional $\mathrm{C}$ added to the mixture $(0.25 \mathrm{wt} \% 0.5 \mathrm{wt} \%$ and $1.0 \mathrm{wt} \%$ with respect to the weight of $\mathrm{M} 2$ ).

\section{Results and discussion}

\section{Thermodynamic calculation of phase diagram}

The equilibrium phase diagram of the cermet $(\mathrm{M} 2+\mathrm{TiCN})$ with respect to the $\mathrm{C}$ content is shown in figure 1. For the calculation of this equilibrium phase diagram, taking into account the presence of TiCN in the steel matrix, the elements $\mathrm{Ti}, \mathrm{C}$ and $\mathrm{N}$ were introduced in the calculation in the mass percentages that correspond to a mixture containing 50 vol\% M2 and 50 vol\% TiCN. The amount of $C$ was varied considering the additional $C$ added to the mixture $(0.25 \mathrm{wt} \%, 0.5 \mathrm{wt} \%$ and $1.0 \mathrm{wt} \%$ with respect to the matrix content). Taking into account all the $C$ present, including that from a) TiCN, b) the M2 matrix and c) the additional $C$ added, the total mass percentage of $C$ varied between $4.37 \mathrm{wt} \%$ for the sample with no additional $\mathrm{C}$ and $5.04 \mathrm{wt} \%$ for the sample containing 1.0 $\mathrm{wt} \% \mathrm{C}$. The total percentage variation of $\mathrm{C}$ is not large since most of the $\mathrm{C}$ is due to the presence of TiCN. The dotted vertical lines, shown in Figure 1, represent the compositions with added free carbon.

Figure 1: Equilibrium phase diagram of cermet $\mathrm{M} 2+50$ vol $\% \mathrm{TiCN}$ as a function of total $\mathrm{C}$ present calculated by ThermoCalc.

From the phase diagram, it can be stated that:

(1) The liquidus temperature decreases when the carbon content increases, as it is expected for a steel matrix. Taking into account this observation, it is important to notice that, at the selected sintering temperature of $1400{ }^{\circ} \mathrm{C}$, only a liquid phase and solid TiCN particles co-exist in the compositions containing more than $0.5 \mathrm{wt} \% \mathrm{C}$, whereas for the compositions with lower $\mathrm{C}$ content a solid $\delta$ phase co-exists with a liquid phase and solid TiCN particles. That means that the quantity of liquid phase is higher for higher $C$ contents, hereby influencing the liquid phase sintering mechanisms and affecting the microstructural development.

(2) TiCN appears as a stable phase in all the regions of the diagram, due to its high melting point and due to the fact that there is no interaction with the Fe from the steel matrix, as some authors have reported [21]. However a small amount of $\mathrm{V}$, originating from the steel matrix, is dissolved into the TiCN phase, which is consistent with the high affinity of $\mathrm{V}$ for $\mathrm{C}$ and the formation of $\mathrm{VC}$; in fact the TiCN-VC system has a complete solid solution because the carbides share a $\mathrm{NaCl}$ type cubic structure and the atomic radii of $\mathrm{V}$ and $\mathrm{Ti}$ are very similar $\left(r_{\mathrm{V}}=0.1925 \mathrm{~nm} ; r_{\mathrm{Ti}}=0.20 \mathrm{~nm}\right)$, fulfilling the Hume-Rothery condition. The metals can be replaced or moved without jeopardizing the stability of the structure inside the solid solution. 
(3) The stable phases present after cooling have different composition depending on the $\mathrm{C}$ content, even though ferrite is present for all the compositions, as well as carbides $\mathrm{M}_{6} \mathrm{C}, \mathrm{M}_{23} \mathrm{C}_{6}$ and TiCN. The compositions of stable phases at $600{ }^{\circ} \mathrm{C}$ as a function of the $\mathrm{C}$ content are summarised in Table 2.

Table 2. Composition of stable phases at $600{ }^{\circ} \mathrm{C}$ as a function of $\mathrm{C}$ content from the calculated phase diagram (wt \%).

From Table 2 the following differences in composition of the different phases can be observed when the $\mathrm{C}$ content increases:

(1) The Cr content of ferrite decreases from $2.3 \mathrm{wt} \%$ to $0.6 \mathrm{wt} \%$

(2) The percentage of $V$ dissolved into the TiCN phase decreases from $1.4 \mathrm{wt} \%$ to $0.6 \mathrm{wt} \%$. These changes in composition are related to the high affinity of alloying elements for $\mathrm{C}$, increasing the content of carbides due to the reaction of $\mathrm{C}$ with elements like $\mathrm{Cr}$ (dissolved in the Fe matrix) or $\mathrm{V}$ (dissolved into the TiCN particles).

(3) MC carbides are enriched in $\mathrm{Cr}$ and Mo $(14,4 \mathrm{wt} \%$ to $28,4 \mathrm{wt} \%$, and, $12,6 \mathrm{wt} \%$ to $29,7 \mathrm{wt} \%$, respectively) while the $\mathrm{V}$ content decreases from $53,4 \mathrm{wt} \%$ to $23,2 \mathrm{wt} \%$.

(4) $\mathrm{M}_{23} \mathrm{C}_{6}$ carbides suffer the opposite trend; $\mathrm{Cr}$ and Mo content are decreased $(51,7 \mathrm{wt} \%$ to 32,1 wt $\%$, and, 17,4 wt $\%$ to 16,0 wt \%, respectively) while the Fe content is increased from $23,7 \mathrm{wt} \%$ to 44,8 wt $\%$.

(5) $\mathrm{W}$ and Mo carbides only appear in compositions with high $C$ content and $M_{6} C$ carbides are not formed in 1wt\% C composition.

The general trends and observations that can be derived from the theoretically calculated phase diagram will prove to be very useful in explaining the observed microstructural and crystallographic differences between conventionally pressed and sintered (CPS) samples, containing equilibrium structures as predicted by the phase diagram, and samples with out-of-equilibrium structures obtained by Spark Plasma Sintering (SPS).

Microstructural study of materials processed by CPS and SPS

Representative microstructures of $\mathrm{M} 2 / \mathrm{TiCN}$ samples with different $\mathrm{C}$ additions (Owt\%, 0.25wt\%, $0.5 \mathrm{wt} \%$ and $1.0 \mathrm{wt} \%)$ are shown in Figure 2. Three main phases can be observed in all the samples: a grey metallic matrix, black TiCN particles and a brighter phase corresponding to the carbides of the alloying elements from the high speed steel matrix. This brighter phase is mainly located at the interface between the metallic matrix and the ceramic TICN particles This interface could be formed after a dissolution-precipitation mechanism of the steel carbides during the sintering process, taking into account that densification takes place by liquid phase sintering. At the beginning of the sintering cycle, during heating, the alloying elements are dissolved in the highspeed steel particles and precipitate in the form of carbides, while, in a later stage, as conventional sintering is a slow process and the temperatures involved in the sintering process are above highspeed steel usage temperatures, the carbides are re-dissolved into the metallic matrix (even in liquid phase) and, during the cooling down, are reprecipitated between the TiCN particles and the matrix, using the TiCN particles as nucleation points.

Figure 2: Microstructures of $[\mathrm{M} 2+\mathrm{x}] / \mathrm{TiCN}(\mathrm{x}=0,0.25,0.5,1.0 \mathrm{wt} \% \mathrm{C})$ samples processed by the Conventional Pressing and Sintering (CPS) route, at $1400^{\circ} \mathrm{C}$ during 60 minutes under vacuum.

Although this explanation is valid for all the materials, some differences can be observed between the theoretically predicted and experimentally detected phases. Microstructures originating from the samples containing 0 and $0.25 \mathrm{wt} \% \mathrm{C}$ are less homogeneous than those containing 0.5 and 1 
wt\% C; the former containing rounded metal matrix zones and showing the existence of bright carbides, appearing not only around the TiCN particles but also precipitated in the metal matrix. For the compositions containing 0.5 and $1 \mathrm{wt} \% \mathrm{C}$, the microstructures are more homogeneous.

The origin of these features can be explained by the theoretical phase diagram shown in Figure 1. It can be seen that compositions containing 0 and $0.25 \mathrm{wt} \% \mathrm{C}$ at the sintering temperature $\left(1400^{\circ}\right.$ C) lie in a region where two solid phases are present, $\delta$ iron and TiCN, whereas the compositions containing $0.5 \mathrm{wt} \% \mathrm{C}$ and $1 \mathrm{wt} \% \mathrm{C}$ contain only TiCN particles and a liquid phase. In the latter case, the larger amount of liquid phase permits the TiCN particles to rearrange their position leading to a more homogeneous distribution in the matrix. In this case, all the carbides from the alloying elements of the steel will precipitate around the TiCN particles. In the compositions with lower $\mathrm{C}$ content, a fraction of the steel particles remains solid and the liquid phase will exist in between the solid steel and the solid TiCN particles; therefore, some carbides will precipitate in the solid state, inside the steel particles, while others will precipitate from the liquid phase using TiCN particles as a nucleation site. Figure 3 schematically describes the difference in phase development between the compositions with low (top) and high (bottom) carbon content.

Figure 3. Schematic representation of microstructure development as a function of $C$ content.

Representative microstructures of materials processed by Spark Plasma Sintering are shown in figure 7. Here also, three main phases can be distinguished, corresponding to the TiCN particles (black contrast), the steel matrix (grey contrast) and the carbides from the alloying elements of the steel (bright phase). Although these phases are the same as the ones found in samples processed by CPS, a significant difference can be observed between CPS and SPS processed samples: in SPS samples, the bright phase is homogeneously distributed throughout the steel matrix as rounded precipitates, whereas in CPS samples this phase is mainly surrounding the TiCN particles, as an interphase with the steel matrix. The bright phase formation in CPS samples has been explained previously. During SPS, however, sintering takes place in the solid state at $1100^{\circ} \mathrm{C}$. Therefore, the alloying elements, dissolved initially in the powder particles, precipitate as carbides inside the steel particles by a short-range diffusion mechanism. These differences in microstructure will be reflected in the density and hardness values, as will be shown later.

Among the SPS samples no significant differences can be observed between the microstructures of the different compositions independent on their carbon content, except for the sample containing $0.5 \mathrm{wt} \% \mathrm{C}$. In this case, there is almost no presence of bright phase, probably due to the dissolution of the carbide forming elements in the Fe matrix during sintering without their reprecipitation during cooling.

Figure 4. SEM microstructures of $[\mathrm{M} 2+\mathrm{X}] / \mathrm{TiCN}(\mathrm{x}=0,0.25,0.5,1.0 \mathrm{wt} \% \mathrm{C})$ samples processed by Spark Plasma Sintering (SPS) route at $1100^{\circ} \mathrm{C}$ and $60 \mathrm{MPa}$ during 10 minutes under vacuum.

\section{$X$-Ray Difraction analysis}

Figure 5 shows the X-ray diffraction patterns of TiCN and M2 raw powders, while Figure 6 shows the diffraction patterns of M2/TiCN samples with different $C$ content sintered by the CPS route. The TiCN powder pattern only presents the peaks corresponding to the FCC structure and the M2 pattern shows that mainly ferritic and austenitic phases are present in the steel matrix powder, with no precipitation of carbides, except for a small peak at about $38^{\circ}$ that could correspond to traces of carbides. The carbide content is much lower than that predicted by the equilibrium phase diagram, which indicates that the alloying elements remain dissolved in the iron particles, which is an intrinsic property of the powder production method by atomization that implies a rapid solidification of the particles. The dissolution of alloying elements in the iron matrix stabilizes the austenitic crystal structure and therefore it is possible to detect retained austenite at room temperature by 
$\mathrm{XRD}$. This austenite is supersaturated and carbides of alloying elements will precipitate from it during sintering [22].

The diffraction patterns for samples containing 0 and $0.25 \mathrm{wt} \% \mathrm{C}$ show peaks that correspond to ferrite ( $\alpha-\mathrm{Fe})$, TiCN and M6C carbides (M: Fe, W, Mo). These phases were predicted by the calculated phase diagram, although MC and M23C6 carbides which also were predicted by the software are not found in the XRD pattern. It is worth mentioning that the most common type of carbides present at room temperature in high-speed steels are the M6C type carbides[23] and that MC type carbides can combine with TiCN due to reactions between the two phases, as they present the same crystalline structure.

The diffraction patterns of the samples containing 0.5 and $1.0 \mathrm{wt} \% \mathrm{C}$ show the same peaks as the samples with lower $C$ content, that is, Ferrite $(\alpha)$, TiCN and $\mathrm{M}_{6} \mathrm{C}$ carbides $\left(\mathrm{Fe}_{3} \mathrm{~W}_{3} \mathrm{C}\right)$, and additional austenitic peaks. The appearance of an austenitic phase in the XRD analysis could be due to the fact that the steel alloying elements re-dissolve into the metallic matrix, hereby stabilizing the austenitic crystal structure.

Figure 5. XRD patterns of TiCN powder and M2 powder

Figure 6. XRD patterns of $[\mathrm{M} 2+\mathrm{x}] / \mathrm{TiCN}(\mathrm{x}=0,0.25,0.5,1.0 \mathrm{wt} \% \mathrm{C})$ samples processed by Conventional Pressing and Sintering (CPS) route at $1400^{\circ} \mathrm{C}$ during 60 minutes under vacuum.

The XRD patterns of the SPS samples are shown in Figure 7. The patterns show peaks corresponding the same phases as were found in the CPS processed samples: Ferrite ( $\alpha-\mathrm{Fe})$, TiCN and $M_{6} C$ carbides (M: Fe, W, Mo). There are no significant differences among the XRD patterns for all the compositions, which imply that there is no influence of the carbon content on the phase constitution of the SPS samples. Moreover, no retained austenite was detected in any of the samples, which is due to the fact that the processing temperature is high enough to promote the precipitation of carbides of the alloying elements dissolved in the austenite present in the initial powder particles, thus permitting its transformation in ferrite during cooling. However, the temperature or time is not high enough to re-dissolve the carbides to stabilise the austenite structure.

Figure 7. XRD patterns of $[M 2+x] / T i C N(x=0,0.25,0.5,1.0 \mathrm{wt} \% \mathrm{C})$ samples processed by Spark Plasma Sintering (SPS) at $1100^{\circ} \mathrm{C}$ and $60 \mathrm{MPa}$ during 10 minutes under vacuum.

\section{Density and hardness}

The Vickers hardness and relative density of the different samples, sintered by either CPS or SPS, are shown in Figure 8. The density is expressed as relative density, that is, values obtained by pycnometry with respect to the theoretical density of each composition. This is a common way to express density in PM products, since it gives an indication of the residual porosity. The relative density of the samples containing 0.5 and $1 \mathrm{wt} \% \mathrm{C}$ is higher than $100 \%$ meaning that they are fully dense. Relative density values exceeding $100 \%$ are due to the reactions occurring during sintering, provoking changes in phase composition and the precipitation of a large number of carbides that change the initial theoretical density value $\left(6.56 \mathrm{~g} / \mathrm{cm}^{3}\right.$ for $0 \% \mathrm{C}$ added). Samples sintered by the CPS route show an increase in density (Fig. 8a) with increasing carbon content due to two factors: (1) the higher content of liquid phase in samples containing $C$ additions higher than 0.3 wt $\%$ at a sintering temperature of $1400^{\circ} \mathrm{C}$ (as predicted by the calculated phase diagram shown in Figure 1) and (2) the formation of $M C^{\prime}$ type carbides in samples with higher $C$ content. Samples processed by SPS present lower densities than CPS samples which is related to the 
lower sintering temperature and the faster sintering cycle, conditions that do not permit liquid phase formation. The densities of the SPS samples, although generally increasing with increasing $\mathrm{C}$ content, present an abnormal low value for $0.5 \mathrm{wt} \% \mathrm{C}$, corresponding to a microstructure containing a small amount of carbides (Figure 4), suggesting that carbides were not precipitated during sintering of this grade, or that they were formed and re-dissolved.

The Vickers hardness values of the CPS samples follow the same trend as their relative densities (Fig. 8b), that is, hardness increases with increasing $C$ content. The highest hardness values (around $1340 \mathrm{HV} 30$ ) are found in samples with $0,5 \mathrm{wt} \% \mathrm{C}$ and $1 \mathrm{wt} \% \mathrm{C}$, which is achieved due to a combination of factors: (1) During sintering, a higher liquid phase content in the metallic matrix is formed leading to the formation of a more homogeneous microstructure, containing carbide of precipitates as an interphase between the metallic matrix and the ceramic TiCN particles, hereby improving thebonding between the phases, as it was explained before; (2) The formation of MC' type carbides with $\mathrm{W}$ and Mo predicted by ThermoCalc software (Table 2), and (3) The presence of retained austenite as was observed by XRD analysis (Fig. 6).

Despite the lower relative density values obtained for samples sintered by SPS, they exhibit a higher hardness compared to CPS samples for the compositions with no C addition and 0.25 wt\% C (960 HV30 vs. 637 HV30 and 1299 HV30 vs. 958 HV30, respectively). This could be due to the finer distribution of carbides in the metal matrix in case of the SPS processed samples. However the maximum hardness achieved in SPS samples is lower than the maximum values in CPS samples, suggesting a more favourable microstructure in case of CPS, or highlighting the fact that a liquid phase is needed for full densification of these composite grades, resulting in concomitant more elevated hardness values.

Figure 8: a) Density values and b) Vickers hardness values of $[\mathrm{M} 2+\mathrm{x}] / \mathrm{TiCN}(\mathrm{x}=0,0.25,0.5,1.0 \mathrm{wt} \% \mathrm{C})$ samples processed by Conventional Pressing and Sintering (CPS) and Spark Plasma Sintering (SPS)

\section{Conclusions}

- The equilibrium phase diagram of the M2-TiCN system, calculated using ThermoCalc software, indicates the following variations when the carbon content of the metallic matrix is varied: (1) The solidus temperature decreases with increasing carbon content, (2) TiCN appears as a stable phase in all regions, (3) $\mathrm{V}$, originating from the high speed steel matrix is dissolved into the TiCN particles forming $(\mathrm{Ti}, \mathrm{V})(\mathrm{CN}),(4)$ when the $\mathrm{C}$ percentage is higher than $0,3 \mathrm{wt} \%$, the metallic matrix is completely coverted in liquid phase at a CPS sintering temperature of $1400{ }^{\circ} \mathrm{C}$, (5) High C content compositions show the formation of (W,Mo)C carbides which are not formed in compositions with lower $C$ percentage and (6) Typical $M_{6} C$ type carbides formed in high speed steels are not formed in the $1 \mathrm{wt} \% \mathrm{C}$ composition.

- A sintering mechanism for CPS samples is proposed. At the beginning of the sintering cycle the alloy elements are dissolved into the high speed steel particles and precipitate in form of carbides; in a further state, the carbides are redissolved into the metallic matrix and then reprecipitate using the TiCN particles as nucleation points. This sintering mechanism is proposed for samples with high $\mathrm{C}$ content which, as it was predicted by Thermocalc diagram, show a lower solidus temperature and higher liquid phase quantity during sintering than samples with low $\mathrm{C}$ content. This differences found in the sintering mechanism are reflected in their microstructures and properties.

- Full density and the highest hardness values are achieved in samples with $0.5 \mathrm{wt} \% \mathrm{C}$ and 1.0 wt $\%$ C sintered by CPS because a completely liquid metallic matrix phase is obtained at the sintering temperature. This leads to the complete dissolution of the carbides of the alloying elements, implying: (1) The reprecipitation of the carbides of the alloy elements using TiCN 
particles as nucleation points and forming an interface between matrix and reinforcement, (2) the stabilization of austenite during cooling, and (3) the formation of $(\mathrm{W}, \mathrm{Mo}) \mathrm{C}$ carbides.

- The sintering mechanism during SPS processing is different compared to CPS processing due to the shorter cycle and lower temperature. Samples processed by SPS sinter in the solid state instead of by the formation of a liquid phase. Thus, the carbides of the alloying elements of steel are homogeneously distributed through the metal matrix due to precipitation during sintering. No further dissolution and re-precipitation mechanism is observed in this case, as a difference to the CPS processing. The final density and hardness is lower than for CPS samples.

\section{Acknowledgements}

The authors would like to acknowledge financial support from the Spanish Ministry of Science and Innovation through the R\&D Project MAT2009-14448-C02 and the Comunidad de Madrid through the program ESTRUMAT-CM (reference S2009/MAT-1585). K. Vanmeensel thanks the Research Fund Flanders (FWO) for his postdoctoral fellowship.

\section{References}

[1] P. Ettmayer, W. Lengauer, Powder Metall Int. 21 (2) (1989) 37-38

[2] H. Pastor, Mater Sci. Eng. A 105-106 (1988) 401-409.

[3] P. Ettmayer, H. Kolaska, W. Lengauer, K. Dreyer, Int. J. Refract. Metals Hard Mater. 13 (1995) 343-351.

[4] W. W. Gruss, Cermets Metals Handbook, ga ed., 16 (1989) pp. 90-97

[5] K. Aigner, W. Lengauer, P. Ettmayer, J. Alloys Compd. 262-263 (1997) 486-91.

[6] E. Gordo, B. Gómez, E. Ruiz-Navas, JM. Torralba, In: World congress on powder metallurgy and particulate materials (PM2008), Washington (USA);8-12 June 2008.

[7] AP. Umanskii, Powder Metall. Metal Ceram. 40 (2001) 637-640

[8] Y. Li, N. Liu, Int. J. Refract. Met. Hard Mater. 26 (1) (2008) 33-40.

[9] V. Rahimi Dizaji, M. Rahmani, Int. J. Mach. Tools Manuf. 47 (2007) 768-72.

[10] J. Kim, S. Kang, Mater Sci. Eng. A 528-(2011) 3090-3095.

[11] J.K. Yang, H. Lee, Mater Sci. Eng. A 209 (1996) 213-217

[12] P. Ettmayer, H. Kolaska, K. Dreyer, Powder Metall. Int.23 (4) (1991) 224-229

[13] Z.A. Munir, U. Anselmi-Tamburini, M. Ohyanagi, J. Mater Sci. 41 (2006) 763-777.

[14] K. Yamazaki, SH. Risbud, H. Aoyama, K. Shoda, J. Mater. Process 56 (1996) 955-65.

[15] S.G. Huang, K. Vanmeensel, O. Van der Biest, J. Vleugels, Int. J. Refract. Met. Hard Mat. 25, 5-6 (2007) 417-422

[16] N. Liu, X. Liu, X. Zhang, L. Zhu, Materials characterization. 59 (10) (2008) 1440-1446

[17] Y. Li, N. Liu, X. Zhang, C. Rong, J. Mat. Processing tech. 206 (2008) 365-373

[18] J. Zackrisson, H. Adrén, Int. J. Refract. Met. \& Hard Mat 17 (1999) 265-273

[19] Y. Zheng, W.J. Liu, W.H. Xiong, Ceram. Int. 30 (2004) 2111-2115.

[20] J.O. Andersson, T. Helander, L. H. Hoglund, P. F. Shi, B. Sundman, Calphad-Computer Coupling of Phase Diagrams and Thermochemistry,26 (2) (2002) 273-313

[21] S. Jonsson. Metallurgical and Materials Transactions B, 29B (1998) 371-384

[22] M. Pellizzari, et al. Materials and Design 32 (2011) 1796-1805

[23] G. Hoyle, High speed steels, Butterworth \& Co, 1988 
Table 1. Characteristics of raw materials.

\begin{tabular}{|c|c|c|c|c|c|}
\hline \multirow{2}{*}{ Raw material } & \multirow{2}{*}{ Supplier } & \multicolumn{2}{|c|}{ Supplier data } & \multicolumn{2}{c|}{ Experimental data } \\
\cline { 3 - 6 } & & $\begin{array}{c}\text { Density } \\
\left(\mathbf{g} / \mathbf{c m}^{\mathbf{3}}\right)\end{array}$ & $\begin{array}{c}\text { Particle size } \\
(\boldsymbol{\mu m})\end{array}$ & $\begin{array}{c}\text { Density } \\
\left(\mathbf{g} / \mathbf{c m}^{3}\right)\end{array}$ & $\begin{array}{c}\text { Particle } \\
\text { size }(\boldsymbol{\mu m})\end{array}$ \\
\hline $\mathrm{TiC}_{0.5} \mathrm{~N}_{0.5}$ & $\begin{array}{c}\text { H.C. } \\
\text { Starck }\end{array}$ & 5.03 & $\begin{array}{c}\mathrm{D} 50=2.0- \\
4.0\end{array}$ & 5.12 & D50 = 3.957 \\
\hline $\begin{array}{c}\text { High Speed Steel, } \\
\text { M2 }\end{array}$ & Osprey & 8.56 & D90<16 & 8.09 & D50=8.147 \\
\hline
\end{tabular}

Table 2. Composition of stable phases at $600{ }^{\circ} \mathrm{C}$ as a function of $\mathrm{C}$ content from the calculated phase diagram (wt \%).

\begin{tabular}{|c|c|c|c|c|c|c|}
\hline $\begin{array}{c}\text { C } \\
\text { content } \\
\text { (wt \%) }\end{array}$ & $\alpha-F e$ & MC & $M C^{\prime}$ & $M_{6} C$ & $\mathrm{M}_{23} \mathrm{C}_{6}$ & TiCN \\
\hline 0 & $\begin{array}{c}96,9 \mathrm{Fe} ; \\
\text { 2,3 Cr; } \\
\text { 0,3 Mo; } \\
\text { 0,3 W }\end{array}$ & $\begin{array}{c}53,4 \mathrm{~V} ; \\
14,4 \mathrm{Cr} \\
12,6 \mathrm{Mo} \\
15,2 \mathrm{C} \\
\text { 2,8 Ti; } \\
\text { 1,3 W }\end{array}$ & - & $\begin{array}{c}43,4 \mathrm{~W} ; \\
28,2 \mathrm{Mo} ; \\
22,0 \mathrm{Fe} \\
2,0 \mathrm{C} ; \\
2,9 \mathrm{~V} ; \\
1,4 \mathrm{Cr}\end{array}$ & $\begin{array}{c}\text { 51,7 Cr; } \\
\text { 23,7 Fe; } \\
\text { 17,4 Mo; } \\
\text { 2,1 W; } \\
\text { 5,1 C; }\end{array}$ & $\begin{array}{c}77,2 \mathrm{Ti} ; \\
11,1 \mathrm{~N} ; \\
10,2 \mathrm{C} ; \\
1,4 \mathrm{~V}\end{array}$ \\
\hline 0.25 & $\begin{array}{c}\text { 97,6 Fe; } \\
\text { 1,7 Cr; } \\
\text { 0,3 Mo; } \\
\text { 0,3 W }\end{array}$ & $\begin{array}{c}46,9 \mathrm{~V} ; \\
17,3 \mathrm{Cr} \\
16,1 \mathrm{Mo} \\
\text { 15,4 C; } \\
2,6 \mathrm{Ti} \\
\text { 1,6 W }\end{array}$ & - & $\begin{array}{r}45,2 \mathrm{~W} ; \\
27,3 \mathrm{Mo} ; \\
22,6 \mathrm{Fe} ; \\
\text { 1,9 C; } \\
\text { 1,6 V; } \\
1,2 \mathrm{Cr}\end{array}$ & $\begin{array}{c}\text { 47,4 Cr; } \\
\text { 28,1 Fe; } \\
\text { 16,9 Mo; } \\
\text { 2,5 W; } \\
\text { 5,0 C }\end{array}$ & $\begin{array}{c}77,3 \mathrm{Ti} ; \\
11,1 \mathrm{~N} ; \\
10,2 \mathrm{C} ; \\
1,3 \mathrm{~V}\end{array}$ \\
\hline 0.5 & $\begin{array}{c}\text { 98,6 Fe; } \\
\text { 0,9 Cr; } \\
\text { 0,3 Mo; } \\
\text { 0,3 W }\end{array}$ & $\begin{array}{c}31,9 \mathrm{~V} ; \\
23,4 \mathrm{Cr} \\
25,1 \mathrm{Mo} \\
14,9 \mathrm{C} \\
2,3 \mathrm{Ti} \\
\text { 2,3 W }\end{array}$ & $\begin{array}{c}78,2 \mathrm{~W} \\
\text { 14,8 Mo; } \\
\text { 6,9 C }\end{array}$ & $\begin{array}{c}45,5 \mathrm{~W} ; \\
27,2 \mathrm{Mo} ; \\
23,9 \mathrm{Fe} ; \\
2,0 \mathrm{C} \\
0,9 \mathrm{Cr}\end{array}$ & $\begin{array}{c}37,5 \mathrm{Cr} ; \\
38,2 \mathrm{Fe} ; \\
\text { 16,1 Mo; } \\
3,2 \mathrm{~W} ; \\
5,0 \mathrm{C}\end{array}$ & $\begin{array}{c}77,6 \mathrm{Ti} ; \\
11,2 \mathrm{~N} ; \\
10,1 \mathrm{C} ; \\
0,9 \mathrm{~V}\end{array}$ \\
\hline 1 & $\begin{array}{l}\text { 99,1 Fe; } \\
\text { 0,6 Cr; } \\
\text { 0,2 Mo }\end{array}$ & $\begin{array}{c}23,2 \mathrm{~V} ; \\
28,4 \mathrm{Cr} \\
29,7 \mathrm{Mo} \\
\text { 14,9 C; } \\
2,2 \mathrm{Ti} \\
\text { 1,4 W }\end{array}$ & $\begin{array}{c}69,4 \mathrm{~W} \\
\text { 23,1 Mo; } \\
\text { 7,4 C }\end{array}$ & - & $\begin{array}{c}32,1 \mathrm{Cr} ; \\
44,8 \mathrm{Fe} ; \\
\text { 16,0 Mo; } \\
\text { 2,1 W; } \\
\text { 5,0 C }\end{array}$ & $\begin{array}{c}77,9 \mathrm{Ti} ; \\
11,2 \mathrm{~N} ; \\
10,1 \mathrm{C} ; \\
0,6 \mathrm{~V}\end{array}$ \\
\hline
\end{tabular}




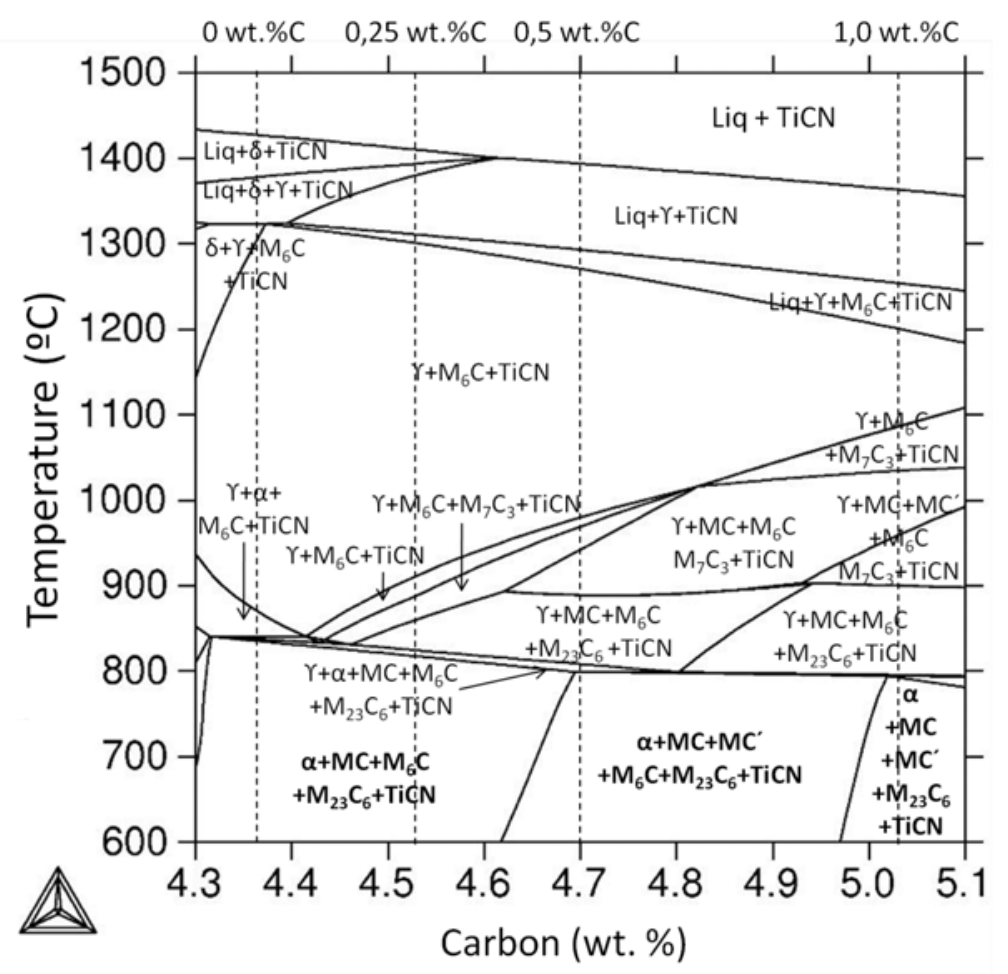

Figure 1: Equilibrium phase diagram of cermet $\mathrm{M} 2+50 \mathrm{vol} \% \mathrm{TiCN}$ as a function of total $\mathrm{C}$ present calculated by ThermoCalc.
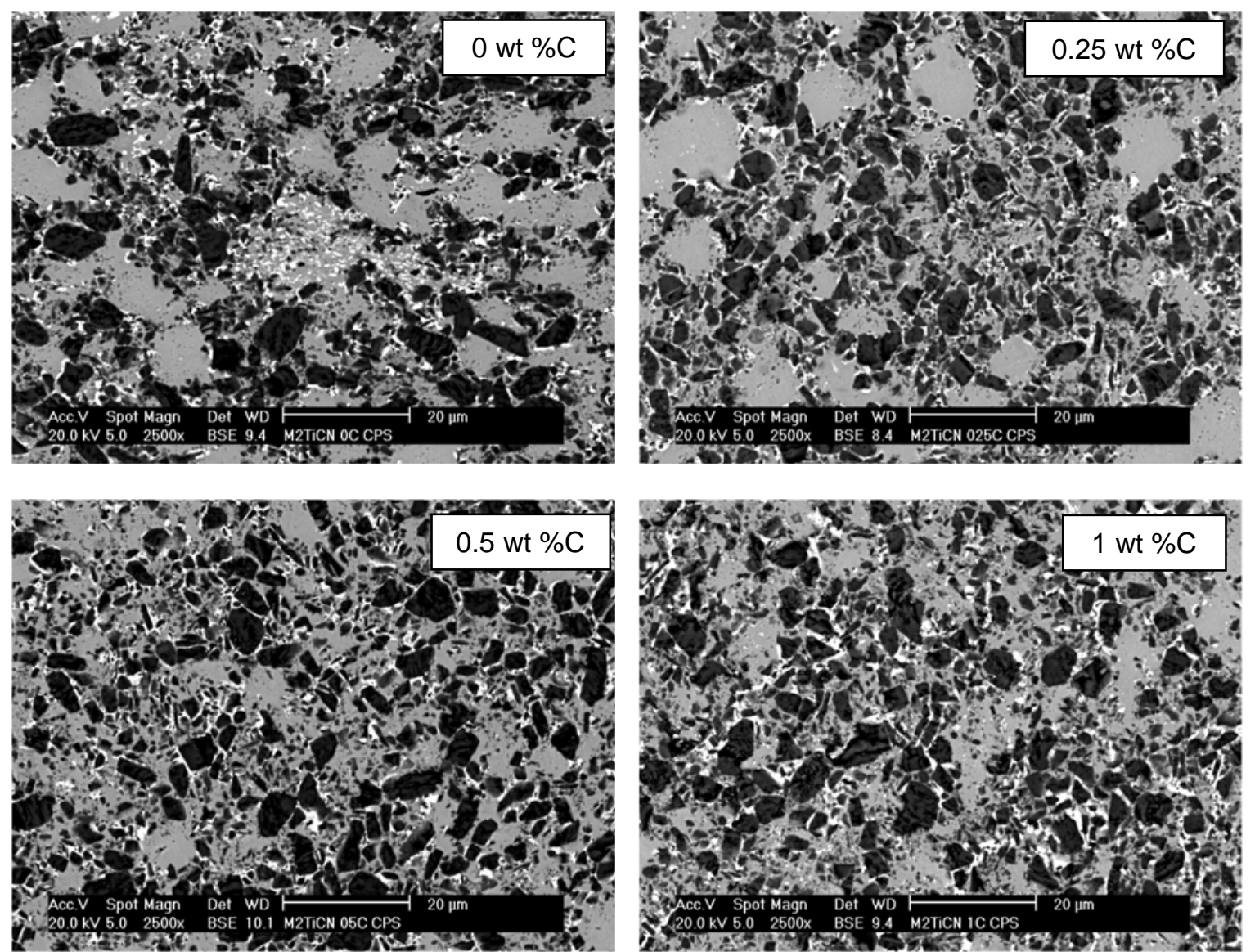

Figure 2: Microstructures of $[\mathrm{M} 2+\mathrm{x}] / \mathrm{TiCN}(\mathrm{x}=0,0.25,0.5,1.0 \mathrm{wt} \% \mathrm{C})$ samples processed by the Conventional Pressing and Sintering (CPS) route, at $1400^{\circ} \mathrm{C}$ during 60 minutes under vacuum. 
Heating

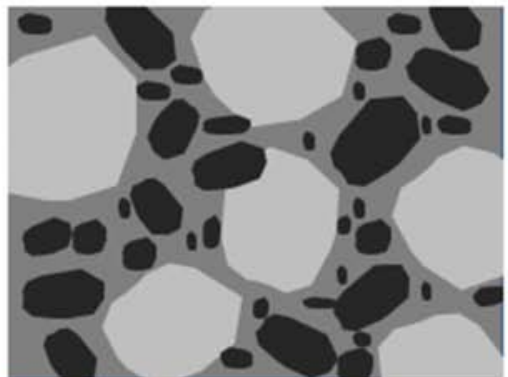

Sintering temperature

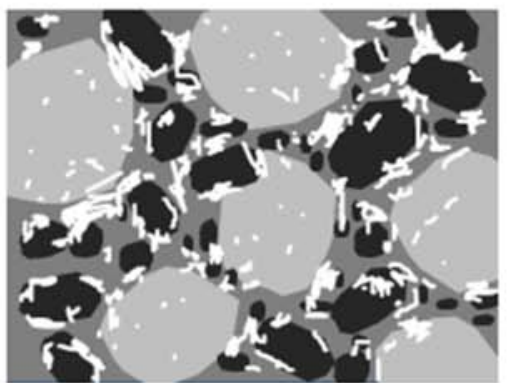

Cooling

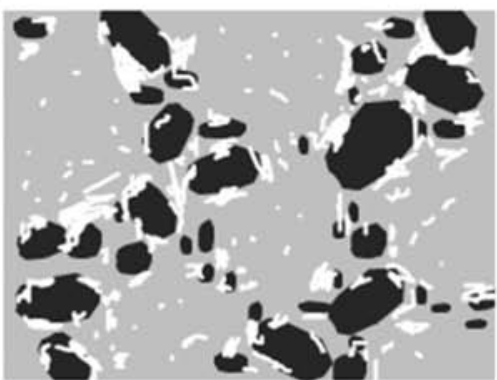

Samples containing 0 wt $\% \mathrm{C}$ and 0.25 wt \% C
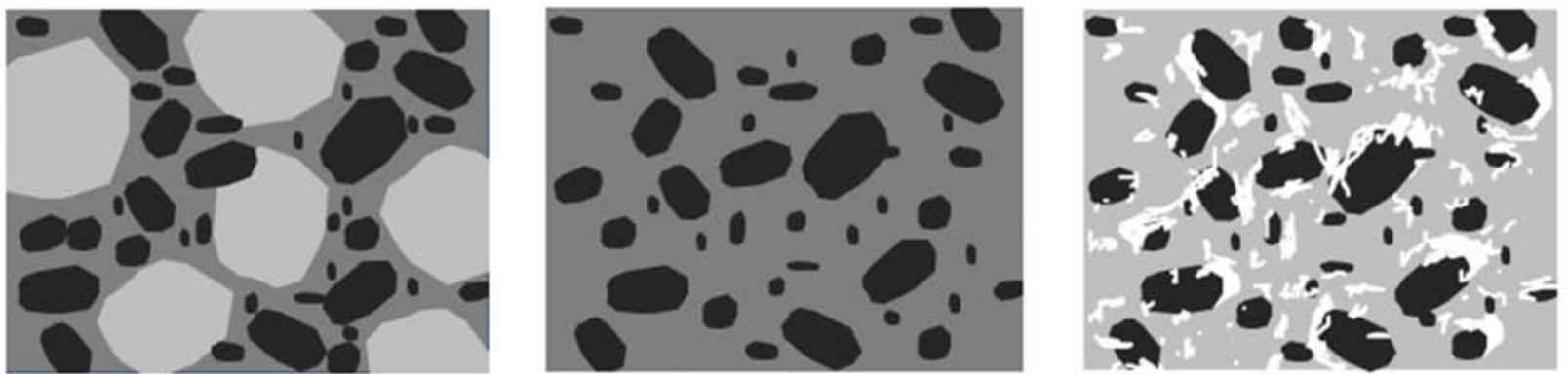

Samples containing 0.5 wt $\% \mathrm{C}$ and 1 wt $\% \mathrm{C}$

Figure 3. Schematic representation of microstructure development as a function of $\mathrm{C}$ content.
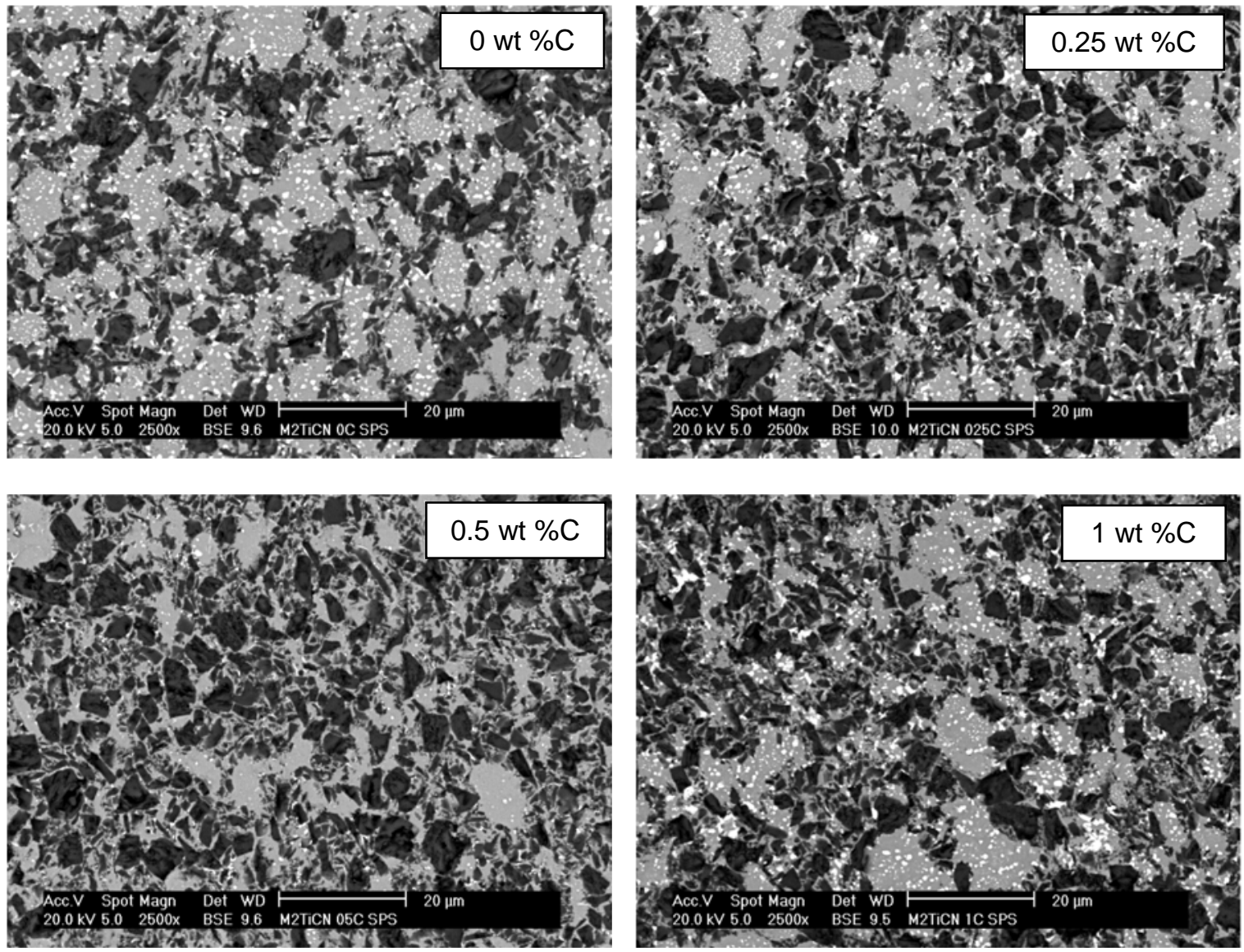

Figure 4. SEM microstructures of $[\mathrm{M} 2+\mathrm{X}] / \mathrm{TiCN}(\mathrm{x}=0,0.25,0.5,1.0 \mathrm{wt} \% \mathrm{C})$ samples processed by Spark Plasma Sintering (SPS) route at $1100^{\circ} \mathrm{C}$ and $60 \mathrm{MPa}$ during 10 minutes under vacuum. 


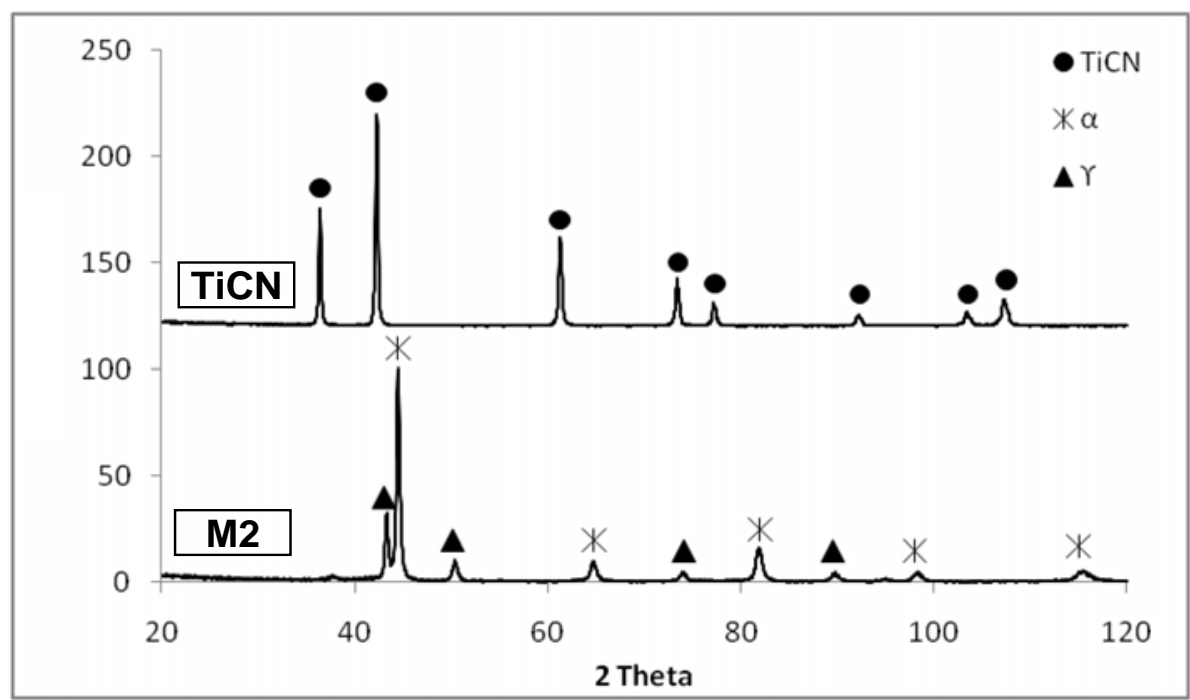

Figure 5. XRD patterns of TiCN powder and M2 powder

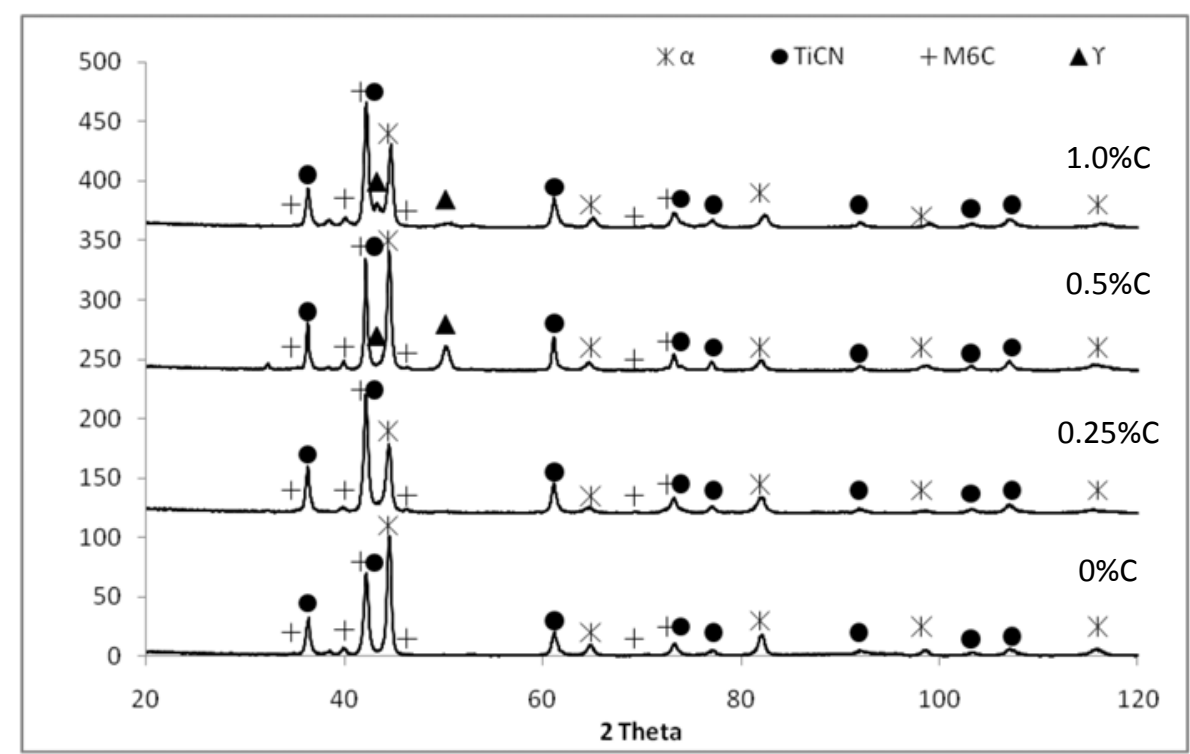

Figure 6. XRD patterns of $[\mathrm{M} 2+\mathrm{x}] / \mathrm{TiCN}(\mathrm{x}=0,0.25,0.5,1.0 \mathrm{wt} \% \mathrm{C})$ samples processed by Conventional Pressing and Sintering (CPS) route at $1400^{\circ} \mathrm{C}$ during 60 minutes under vacuum. 


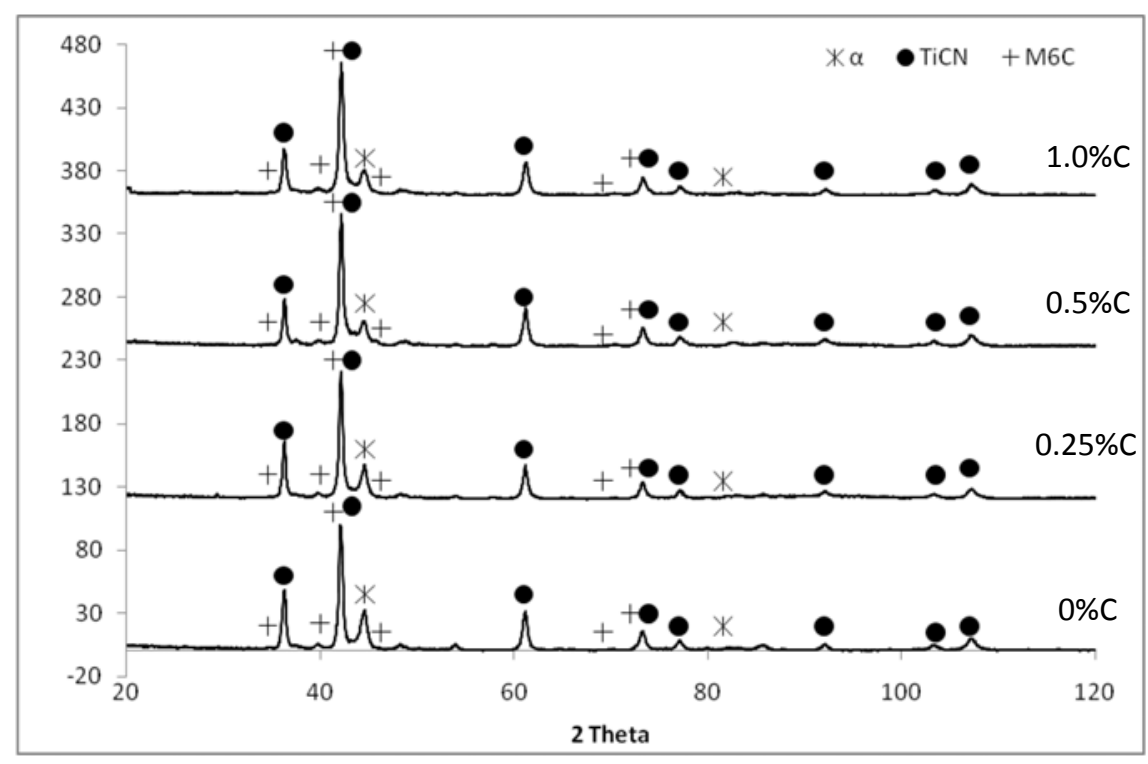

Figure 7. XRD patterns of $[\mathrm{M} 2+\mathrm{x}] / \mathrm{TiCN}(\mathrm{x}=0,0.25,0.5,1.0 \mathrm{wt} \% \mathrm{C})$ samples processed by Spark Plasma Sintering (SPS) at $1100^{\circ} \mathrm{C}$ and $60 \mathrm{MPa}$ during 10 minutes under vacuum.
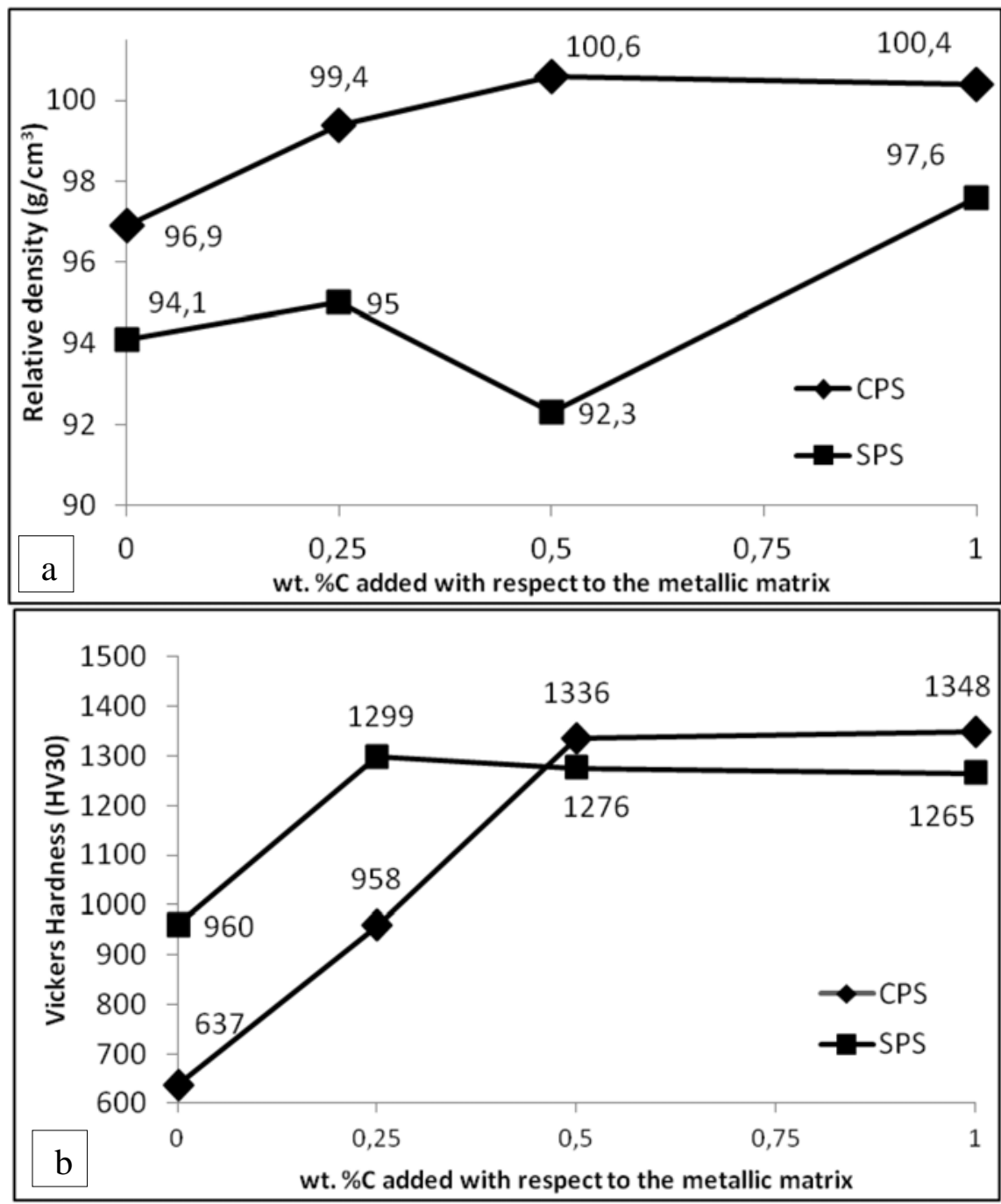

Figure 8: a) Density values and b) Vickers hardness values of $[\mathrm{M} 2+x] / \operatorname{TiCN}(x=0,0.25,0.5,1.0 \mathrm{wt} \% \mathrm{C})$ samples processed by Conventional Pressing and Sintering (CPS) and Spark Plasma Sintering (SPS) 